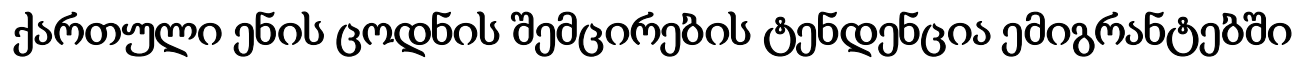

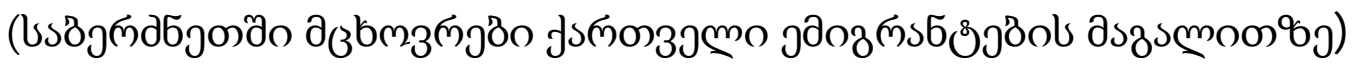

\author{
dojsdj $\partial s 6 s 6 s$

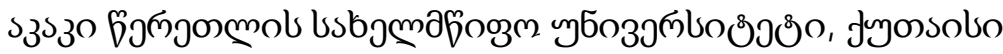

https://doi.org/10.52340/idw.2021.509

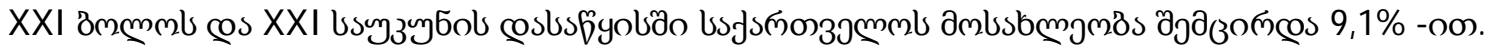

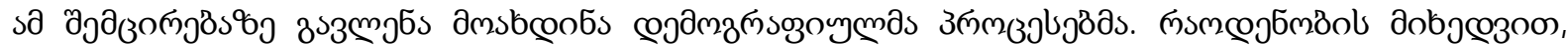

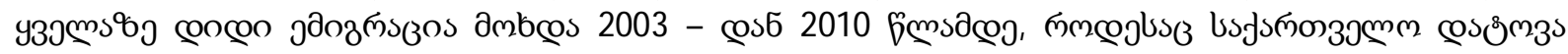

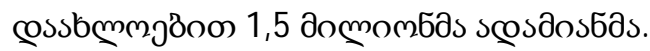

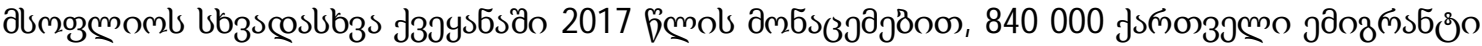

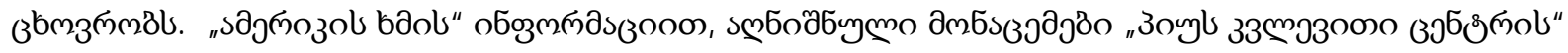

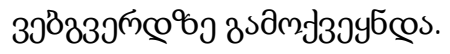

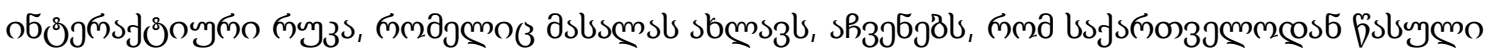

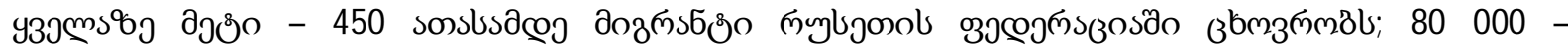

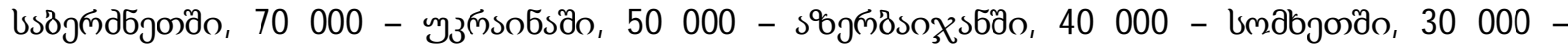

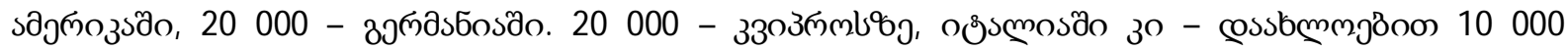

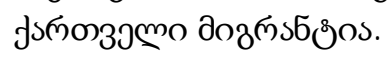

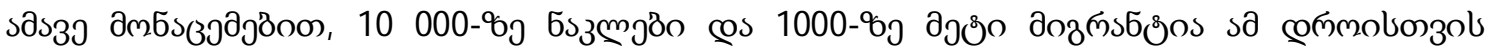

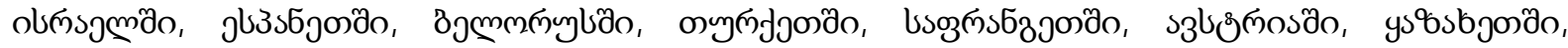

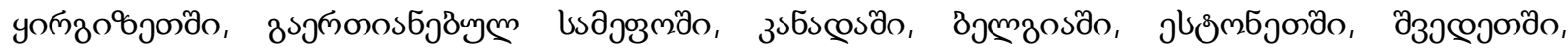

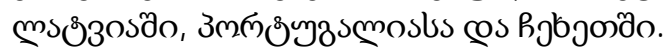

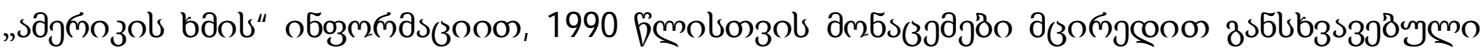

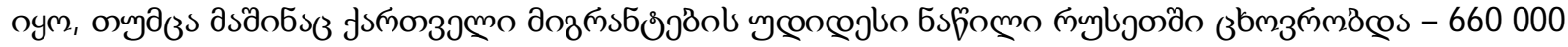

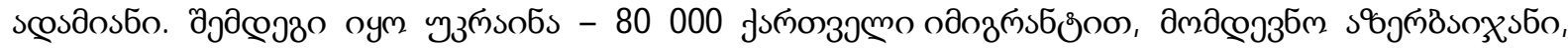

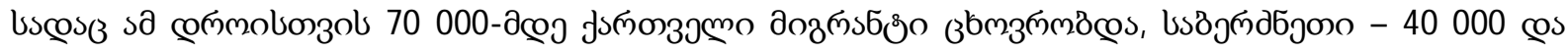

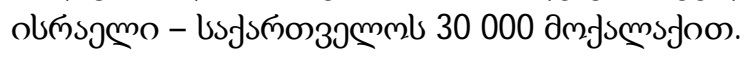

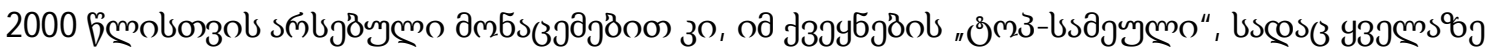

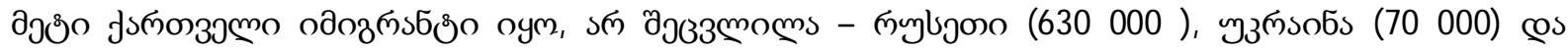

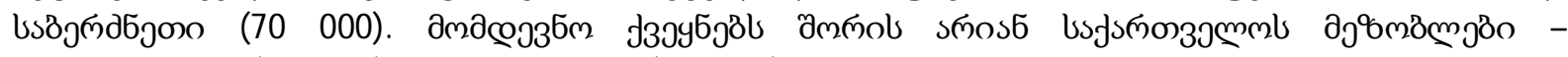

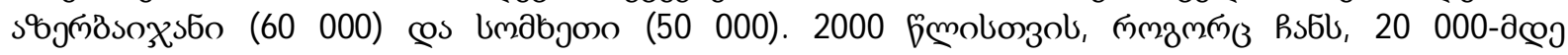

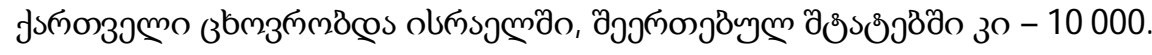

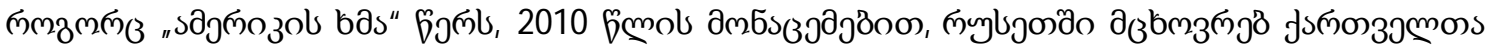

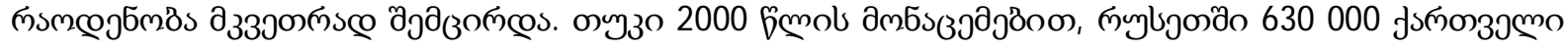

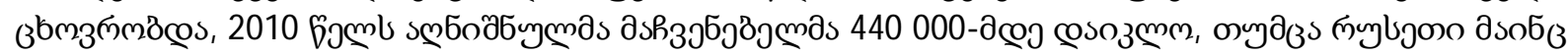

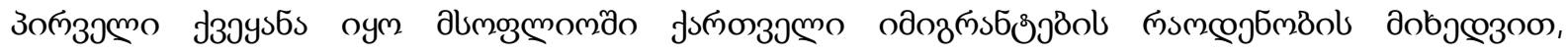

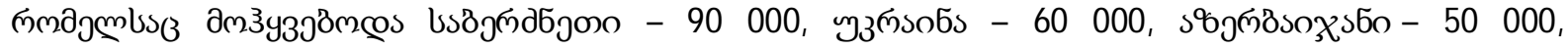

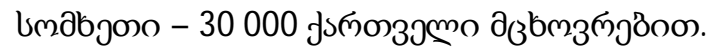

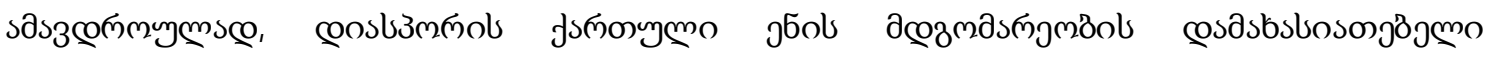

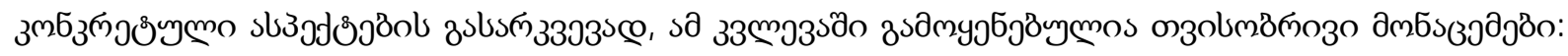




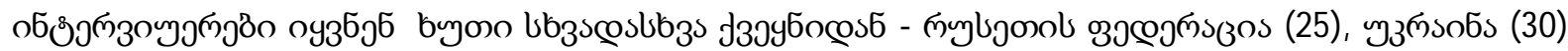

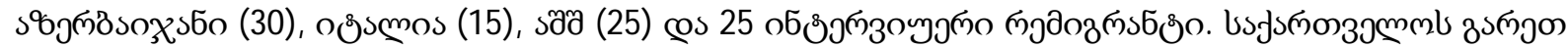

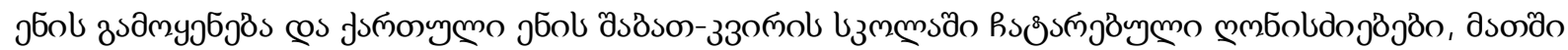
дmbsfongmöol hsonзmon.

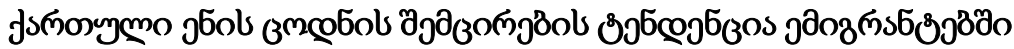

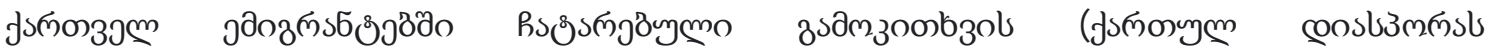

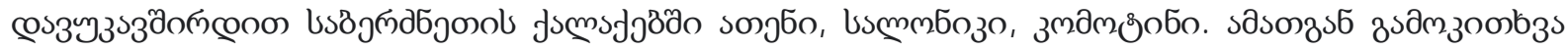

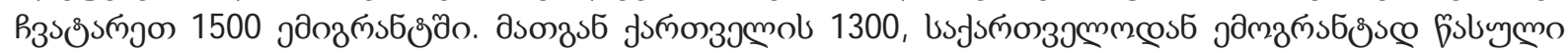

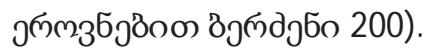

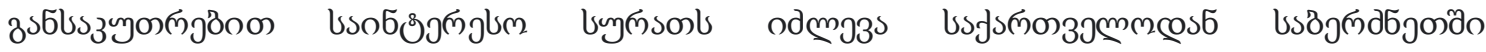

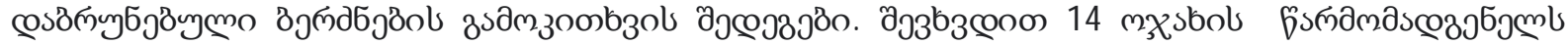

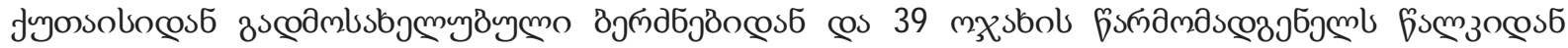

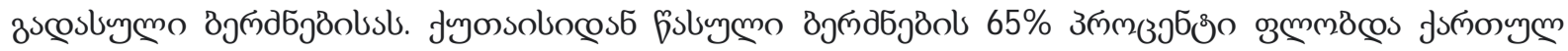

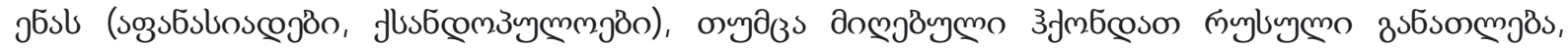

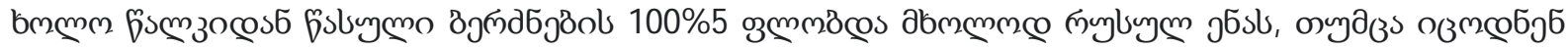

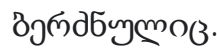

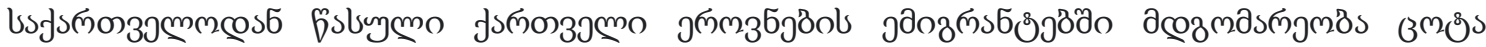

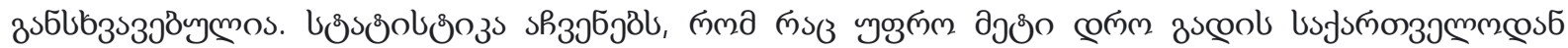

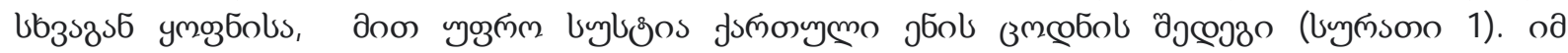

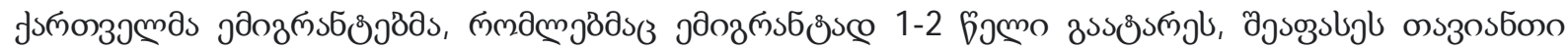

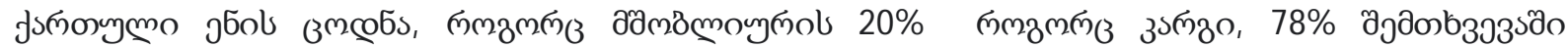

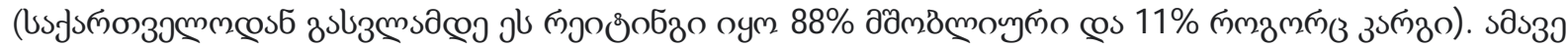

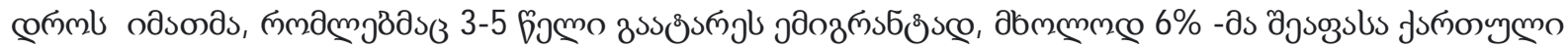

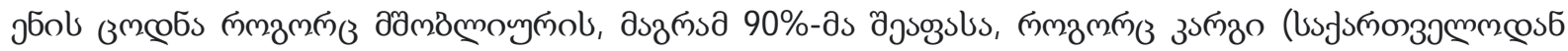

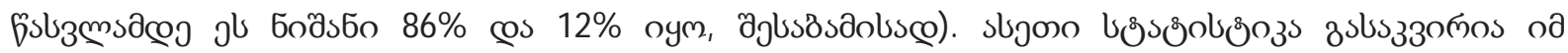

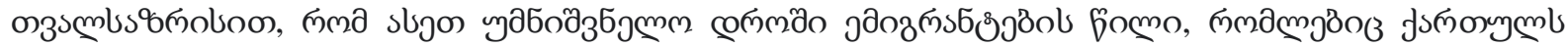

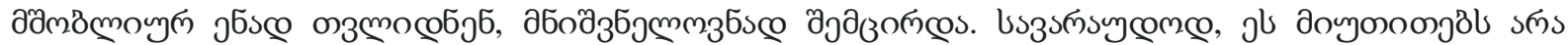

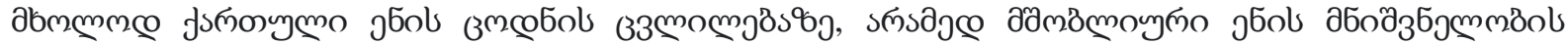

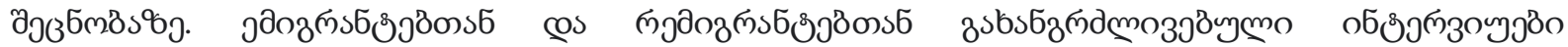

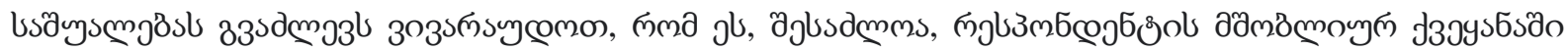

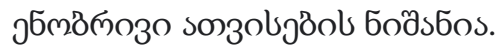

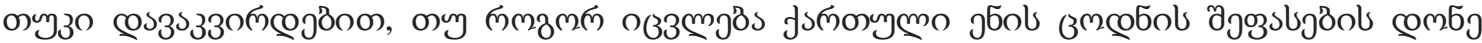

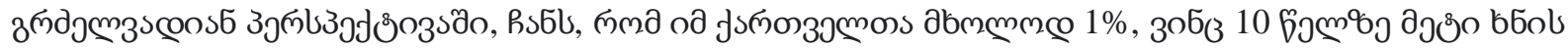

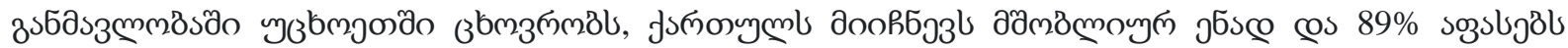

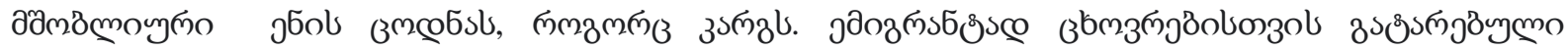

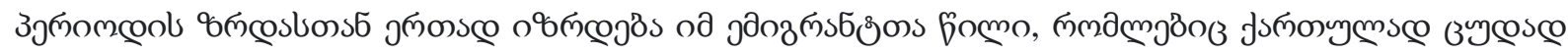

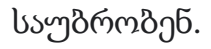


3ॅัsозозо 1.

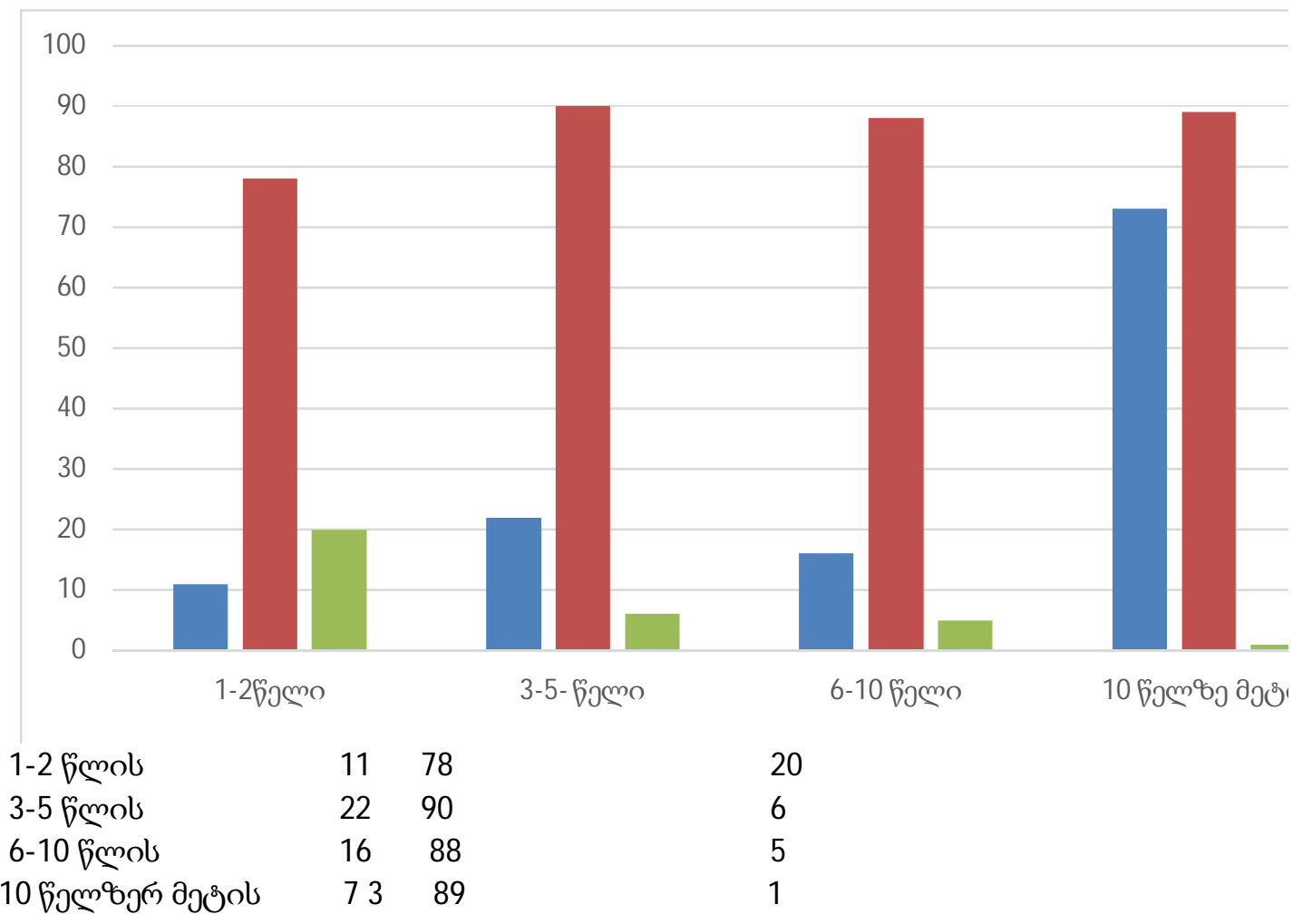

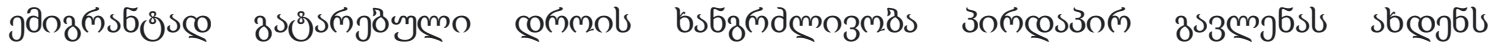

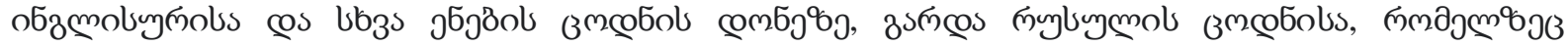

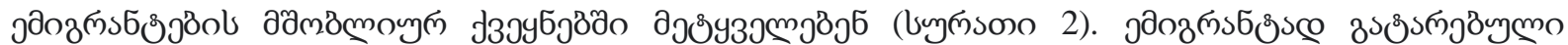

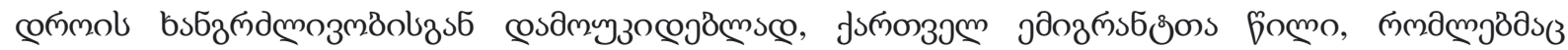

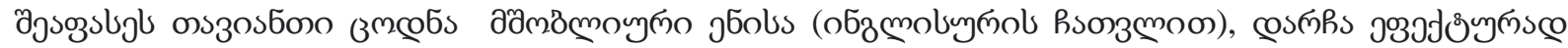

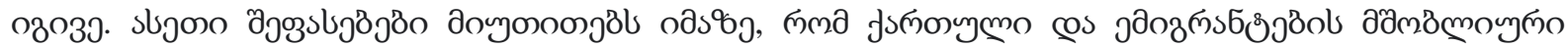

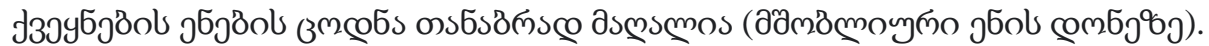

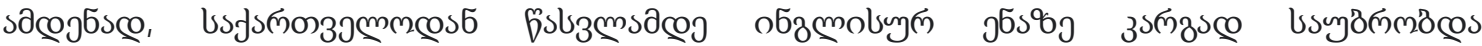

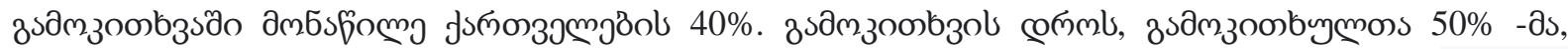

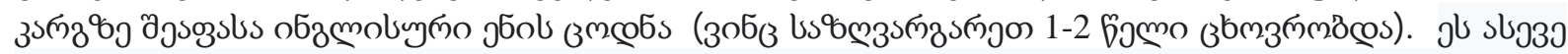

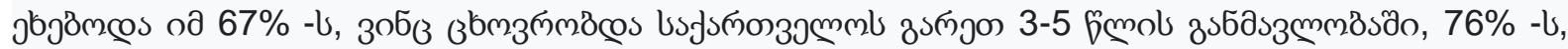

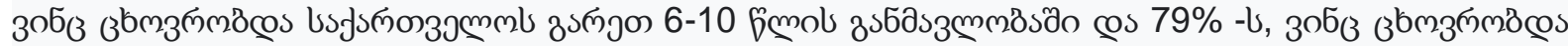

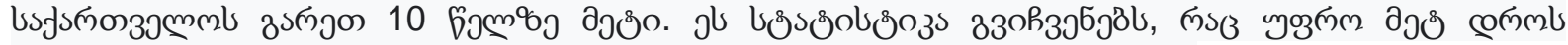

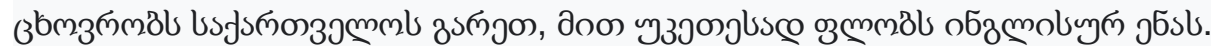

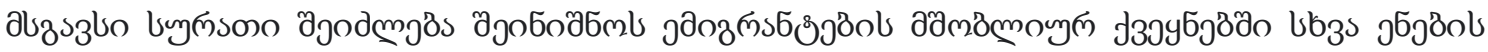

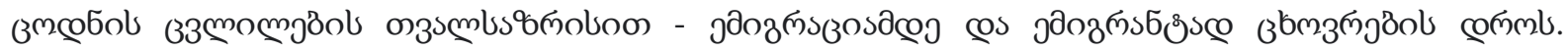

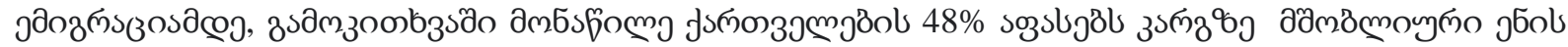

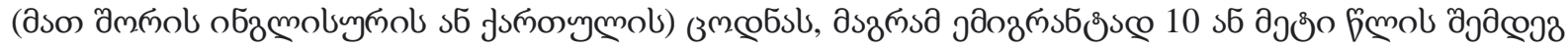

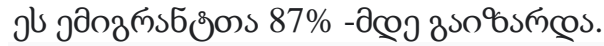




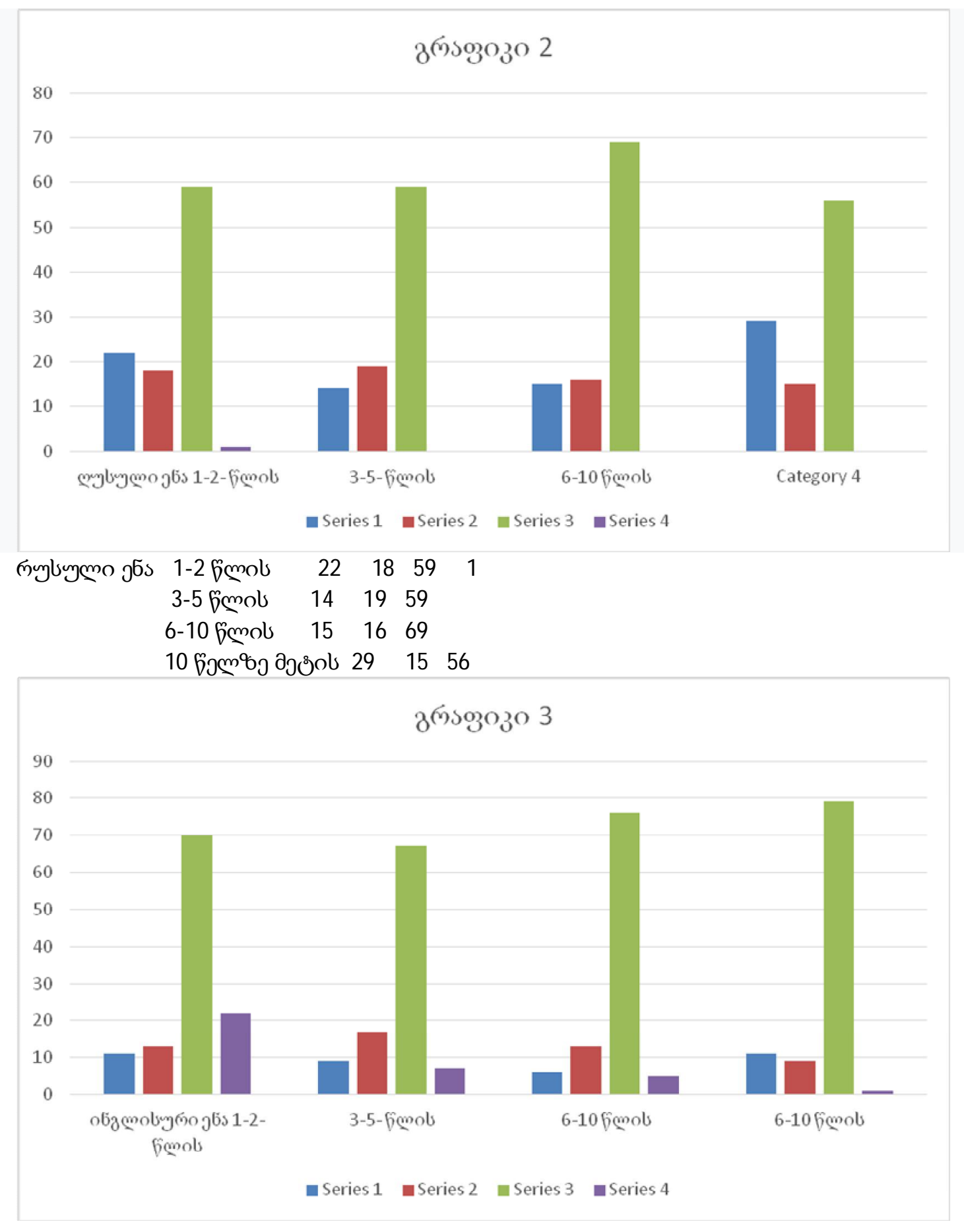

obamolyyno jбs 1-2 fmols

3-5 $\mathrm{bmols}$

$\begin{array}{llll}11 & 13 & 70 & 22\end{array}$

6-10 $6 \mathrm{mols}$

$\begin{array}{llll}9 & 17 & 67 & 7\end{array}$

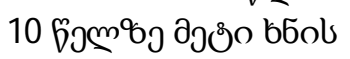

$\begin{array}{llll}6 & 13 & 76 & 5\end{array}$

$\begin{array}{llll}11 & 9 & 79 & 1\end{array}$ 


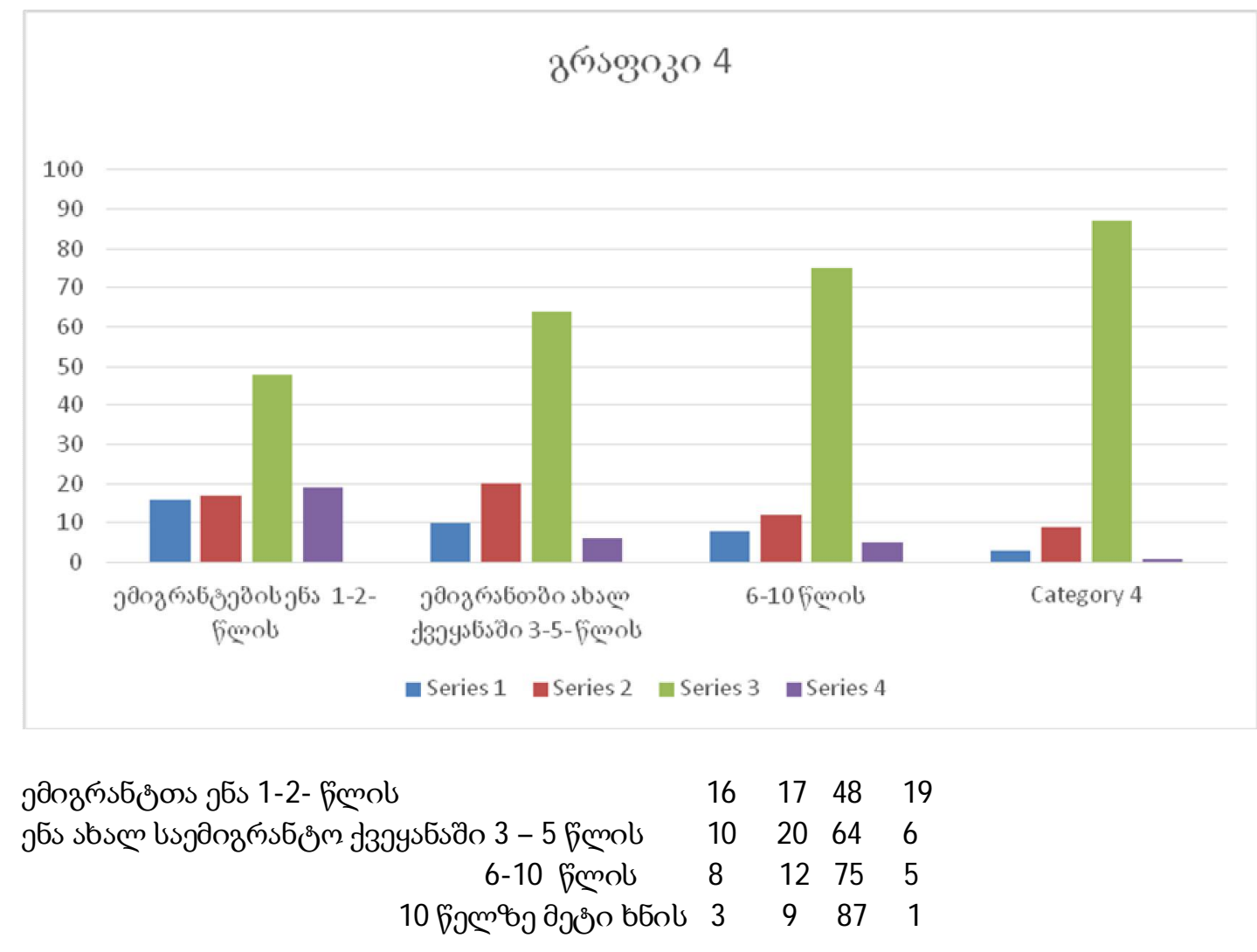

\title{
Georgian and Language Competition in the Diaspora (Emigrant community)
}

Mikadze Manana

Akaki Tsereteli state University, Kutaisi

\begin{abstract}
At the End of the XXth and at the beginning of the XXIst Century the population of Georgia has decreased by $9,1 \%$. This decrease has been influenced by demographic processes as well as by those connected with long-term emigration. In terms of numbers, the largest emigration occurred bertween 2003 and 2010 when approximately 1,5 mln people left Georgia. Emigration has decreased in recent years; however, every year several tens of thousands of Georgian nationals leave Georgia. For an extended period of time Georgia lacked any systematic studies grounded in statistics regarding the lives of those Georgian nationals who had emigrated; however, in recent years, the number of researchers studying the Georgian Diaspora continues to extand. One of the most extensive studies devoted to researching the life of the diaspora is the study the Georgia's emigrant communities: national identity, translational relationships and the politics of the diaspora, which has conducted in 2014-2016 by a research group from the Ministry of Foreign affairs of Georgia. The Georgian languuage situation in the diaspora is analyzed based on the statistics from this study.

The Georgian language is one of the fundamental components of Georgiam national identity and to which special attention is devoded in language policy as well as in planning documents relating to the diaspora and remigration policies. We have not yet sound such a policy system on official Websites. How does knowledge and use of Georgian change after moving out of Georgia?
\end{abstract}


How is it influenced by competition with other languages? What importance is given by parents to their children's Georgian language profocoency and its maintenance? How is Georguan maintained when living outside of Georgia? Answers to these questions are given in this article based on the most extensive and multifaceted survey data of emigrants from Georgia available to date.

At the same time, in order to give a deeper interpretation of particular aspects characterizing the Diaspora Georgian language situation, qualitative data are utilized in this study: from 90 indepth interviews from five different countries - RussianFederation (25), Ukrtaine (30), Azerbaijan (30), Italy (15), USA (25) along with 25 interviews with remigrants (Georgian nationals who have returned to Georgia after a number of years spent as emigrants. In the interviews, emigrants and remigrants discussed the experience of Georgian language use outside of Georgia, and Georgian Language weekend school activities, including participation in these. They also discuss the support necessary for regaining Georgian language proficiency and further developing this profocoency after their return to Georgia.

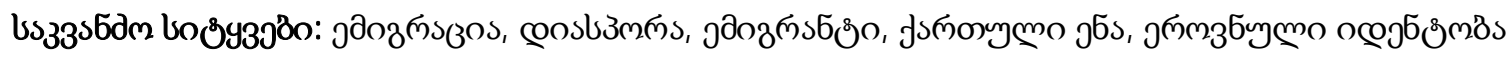
Key words: Emigration, Diaspora, Emigrant, Georgian language, national identity 